\title{
NUMERICAL STUDY ABOUT THE INFLUENCE OF WALL ANGLE ABOUT MAIN STRAINS, THICKNESS REDUCTION AND FORCES ON SINGLE POINT INCREMENTAL FORMING PROCESS
}

\author{
OLEKSIK Valentin \\ Professor / Ph.D., Faculty of Engineering / Department of Industrial Machinery and Equipment, \\ "Lucian Blaga" University of Sibiu, Sibiu, Romania, valentin.oleksik@ulbsibiu.ro
}

\begin{abstract}
The current paper aims to study, using numerical simulation, the influence of the wall angle on the single point incremental forming process. For the analysis there has been used the LS-Dyna software and three explicit dynamic analyses were run for three parts with wall angles of $45^{\circ}, 55^{\circ}$ and $65^{\circ}$. The factors taken into account are the main strains, the thickness reduction and the forces on three directions. The material data introduced into the simulation were determined based on an uniaxial traction test on an Instron 5587 testing machine and the Aramis system was used as optical extensometer.
\end{abstract}

Key words: Wall angle, Incremental Forming, Numerical simulation, Explicit analysis, Main strains, Thickness reduction, Forces

\section{Introduction}

In the last few years, the whole world is seeking to increase the flexibility of metal forming processes. This can be done by increasing the flexibility of the forming tools. This is sought both for bulk forming processes and for sheet metal forming processes. For the mentioned process, forming is done through a partial contact between a punch that moves on a programmed trajectory and the metal or other material sheet. The SPIF can be carried out either on a CNC machine tool or using a robot that follows a specified trajectory.

Alwood and Ustunomiya (2006) present the main flexible sheet metal forming processes, such as flexible spinning, incremental forming, flexible hammering, flexible bending and determines the strong points and the weak points for each of these. Among these procedures, the SPIF or TPIF incremental forming ones are of special importance due to their applicability in various domains. Yamashita et al. (2008) realised the numerical simulation of SPIF for several types of trajectories.

Experimental researches related to SPIF were mainly directed at determining the forces in the process. Duflou et al. (2007) analyse the forces at SPIF and the influence of the step, of the diameter of the tool, of the wall angle and of the initial blanksheet thickness of the on these forces. Fiorentino et al (2009) determined the forces on three directions at TPIF with positive die. Filice et al. (2006) have emphasised the importance of controlling the incremental forming process based on monitoring the forces in the process.

The precision of parts obtained by SPIF was studied by Ambrogio et al. (2007). Bambach et al (2009) present various forming strategies, both for SPIF and for TPIF, in order to increase the geometrical precision of parts.

Hussain et al. (2007), have studied the formability of various materials at SPIF and TPIF, but also the determining of forming limit diagrams specific for these processes. Capece et al. (2007) have identified through experimental research and numerical simulations the maximum slope angle for pyramidal frustum and conical frustum type parts obtained through SPIF.

Attanasio et al. (2008) studied the optimisation of the punch trajectory at SPIF using two trajectory types: one with a constant step depth and one with variable step depth and a limit scallop value. In a first phase, they presented the impact of the punch trajectory type and of other parameters on the precision of parts obtained through incremental forming. Behera et al. (2013) has used an algorithm for error prediction tool for incremental forming and presented tool path strategies using multivariate adaptive regression.

If the first studies on incremental forming have analysed the behaviour of metallic materials such as steel sheets or aluminium sheets, Martins et al. (2009) studied the behaviour at incremental forming of 
plastic materials. Jackson et al. (2008) realised a comparative study regarding the behaviour at SPIF of sandwich panels with metallic sheets.

\section{Preparing of numerical analysis}

In order to emphasize the influence of the wall angle on incremental forming process were run three dynamic explicit analyses (with Ls-Dyna), all for the same geometrical type of part (frustum of pyramid) and all for the same material. The selected material was DC04 steel with a initial thickness of $t=0.4 \mathrm{~mm}$. In order to identify the material data, there have been carried out uniaxial tension tests for samples extracted at $0^{\circ}, 45^{\circ}$ and $90^{\circ}$ towards the rolling direction. The tests were done on an Instron 5587 tension, compression and buckling testing machine. There were extracted five test samples for each of the aforementioned directions. The measured data were the E modulus, Poisson coefficient, yield stress, $\mathrm{K}$ - strength coefficient, $\mathrm{n}$ - hardening coefficient and the anisotropy coefficient (R). For determining the anisotropy there has been used an Aramis optical extensometer. Figure 1 presents the true stress - true strain graphs for DC04 steel of $0.4 \mathrm{~mm}$ thickness for samples extracted on a direction parallel to the rolling direction and figure 2 presents an image taken with the Aramis optical extensometer during determining the anisotropy.

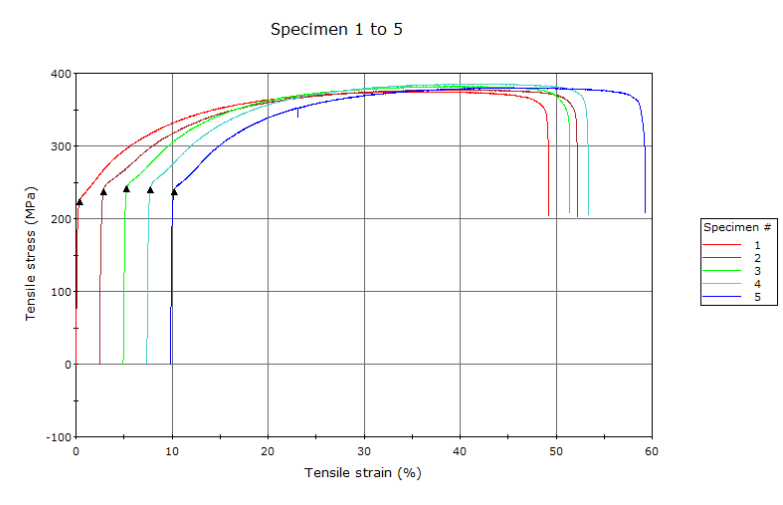

Figure 1: True stress - true strain curve for DC04 steel

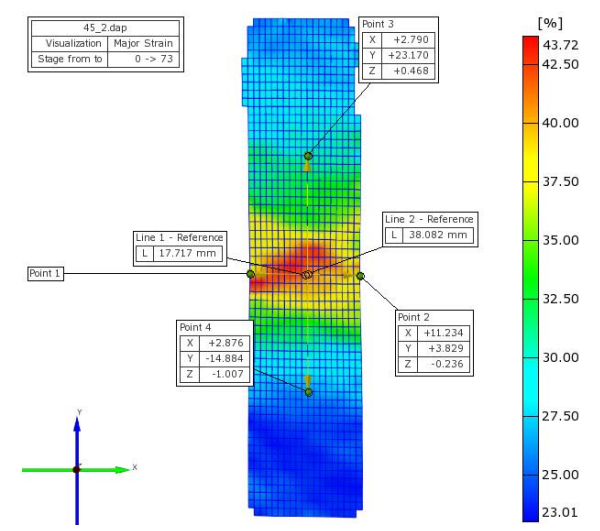

Figure 2: Measuring the anisotropy on major strain variation image for $\mathrm{DC04}$ steel

The material data obtained from the uniaxial tension tests are: Young modulus $-\mathrm{E}=214000 \mathrm{MPa}$, Poisson coefficient $-v=0.29$, yield stress $-Y_{s}=223 \mathrm{MPa}$, hardening coefficient $-\mathrm{n}=0.22$, strength coefficient $-\mathrm{K}=461 \mathrm{MPa}$ and the anisotropy coefficient $-\mathrm{R}=1.165$. For the frustum of pyramid part the author chose a spiral trajectory because there aren't many vertical penetrations of the punch and implicitly many areas with concentrations of strain and thinning. The modelled and meshed elements are: blank, die, blankholder and punch. The blank was considered to be deformable and the other three to be non-deformable solids. Figure 3 present the mesh of the blank and the punch positioned at the end of the trajectory. It can be noticed that the mesh of finite elements associated to the blank's geometry does not undergo a remeshing during the simulation because the author chose a different mesh for the area on which the blankholder works than the one in the forming area. For the simulation there was used the material model number 37 . This material has transversal anisotropic elasto-plastic behaviour. The element type was Shel 163. A 5/6 shear factor was used. The number of integration points was 9 . 


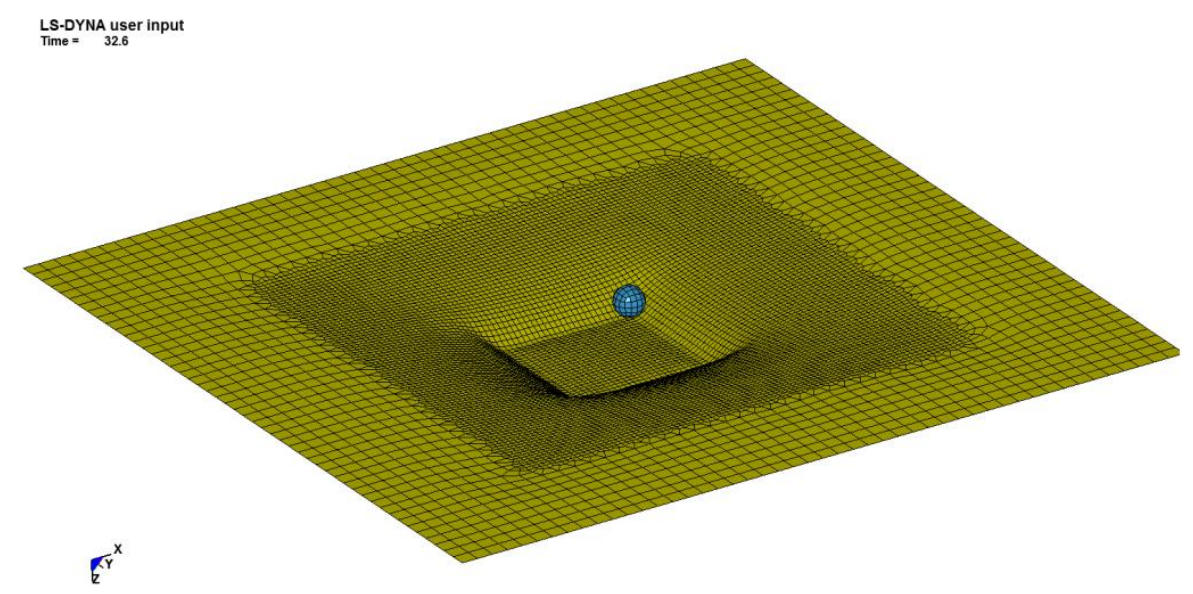

Figure 3: The mesh of the blank and the punch positioned at the end of trajectory

\section{The result of finite element analysis}

The results of the finite element analysis were focused on the variations of the major strain (Figure 4), variations of the minor strain (Figure 5), variations of the thickness reduction (Figure 6) and variations of the forces during the incremental forming process (Figure 7 for the part with $45^{\circ}$ wall angle). The results of the finite element analysis, related to the maximum values of the above mentioned parameters, are presented in Table 1. Figure 4 presents the major strain variations for the three different parts. There can be noticed a localization of the maximal values of the major strain on the faces of the frustum of pyramid alongside the trajectories followed by the punch. The larger the wall angle, the more pronounced the localization of the major strain is. The maximum values obtained for the main strain are: $0.2631[\mathrm{~mm} / \mathrm{mm}]$ - for the part with $45^{0}$ wall angle; $0.3579[\mathrm{~mm} / \mathrm{mm}]$ - for the part with $55^{0}$ wall angle and $0.4108[\mathrm{~mm} / \mathrm{mm}]$ - for the part with $65^{0}$ wall angle.

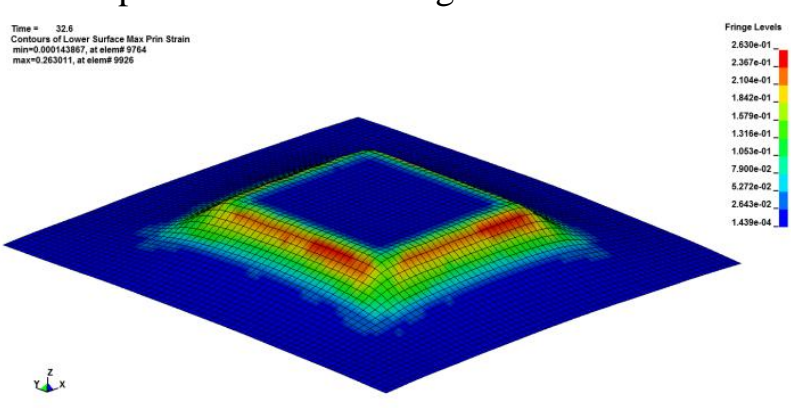

( a )

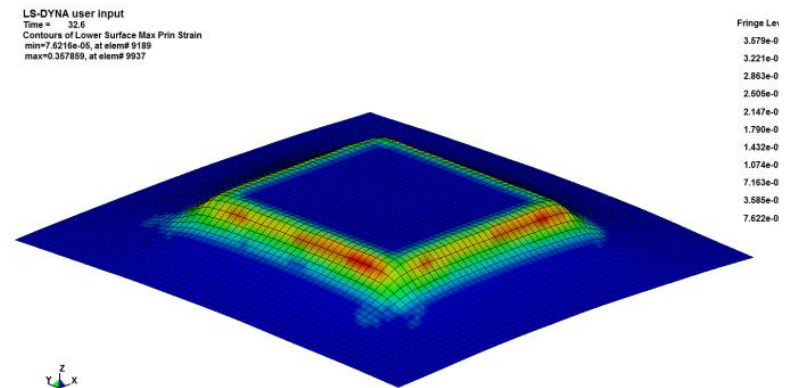

( b )

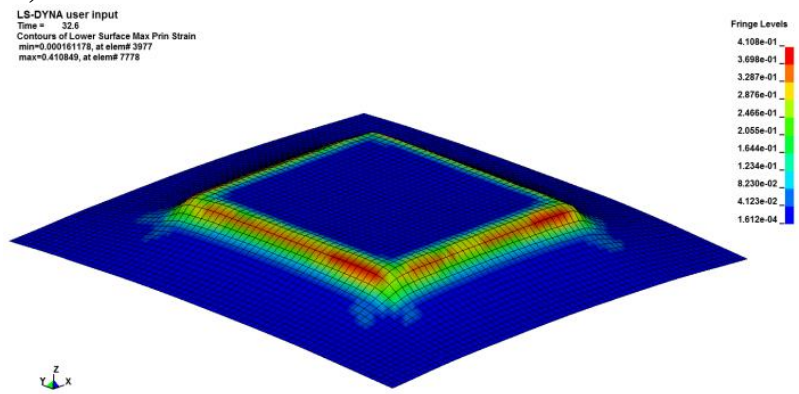

(c)

Figure 4: Major strain variation for: the part with $45^{\circ}$ wall angle (a); the part with $55^{0}$ wall angle (b); the part with $65^{\circ}$ wall angle (c)

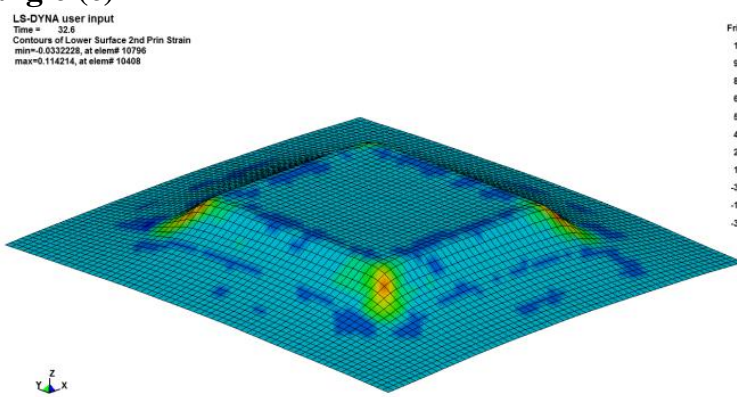




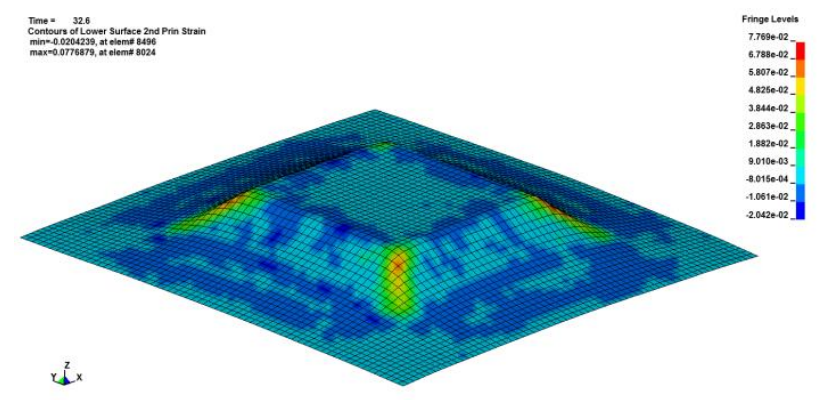

( a )

( b )

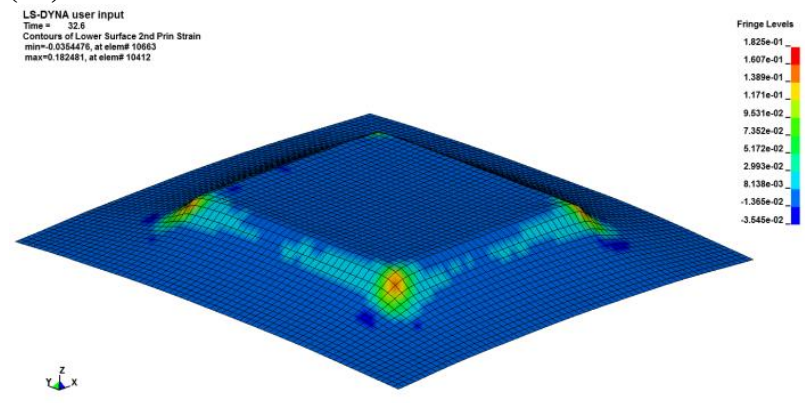

(c)

Minor strain variation for: the part with $45^{\circ}$ wall angle (a); the part with $55^{\circ}$ wall angle (b); the part with $65^{\circ}$ wall angle (c)

Table 1: The results of numerical simulations

\begin{tabular}{|c|c|c|c|c|c|c|}
\hline Wall angle & $\begin{array}{c}\text { Major strain } \\
{[\mathbf{m m} / \mathbf{m m}]}\end{array}$ & $\begin{array}{c}\text { Minor strain } \\
{[\mathbf{m m} / \mathbf{m m}]}\end{array}$ & $\begin{array}{c}\text { Thickness } \\
\text { reduction } \\
{[\mathbf{\%}]}\end{array}$ & $\begin{array}{c}\text { Maximum } \\
\text { value of Fz } \\
{[\mathbf{N}]}\end{array}$ & $\begin{array}{c}\text { Maximum } \\
\text { value of } \mathbf{F x} \\
{[\mathbf{N}]}\end{array}$ & $\begin{array}{c}\text { Maximum } \\
\text { value of Fy } \\
{[\mathbf{N}]}\end{array}$ \\
\hline $\mathbf{4 5}^{\mathbf{0}}$ & 0.2631 & 0.0739 & 25.63 & 264.8 & 113.46 & 82.44 \\
\hline $\mathbf{5 5}^{\mathbf{0}}$ & 0.3579 & 0.1142 & 35.16 & 335.6 & 160.74 & 110.3 \\
\hline $\mathbf{6 5}^{\mathbf{0}}$ & 0.4108 & 0.1825 & 43.35 & 342.41 & 185.94 & 140.7 \\
\hline
\end{tabular}

Figure 5 presents the minor strain variations for the three different parts. There can be noticed a localization of the maximal values of the minor strain at the corners of the frustrum of pyramid at the end of the trajectories followed by the punch, with higher values towards the part bottom and lower values towards its base. Basically, for the part with a wall angle of $65^{\circ}$, the minor strain is localized only on the part's corner. The maximum values obtained for the minor strain are: $0.0739[\mathrm{~mm} / \mathrm{mm}]$ - for the part with $45^{0}$ wall angle; $0.1142[\mathrm{~mm} / \mathrm{mm}]$ - for the part with $55^{0}$ wall angle and $0.1825[\mathrm{~mm} / \mathrm{mm}]-$ for the part with $65^{\circ}$ wall angle.

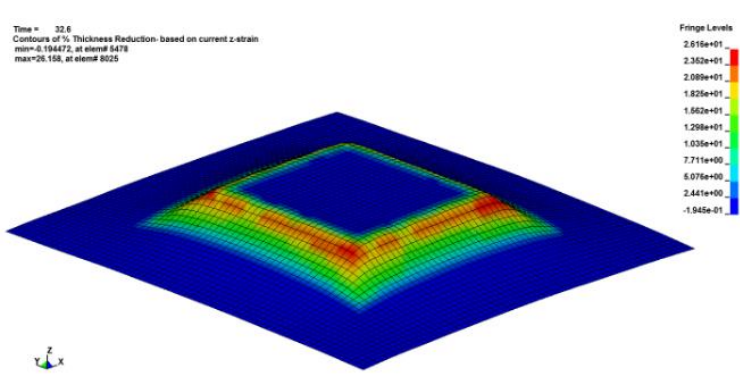

(a)

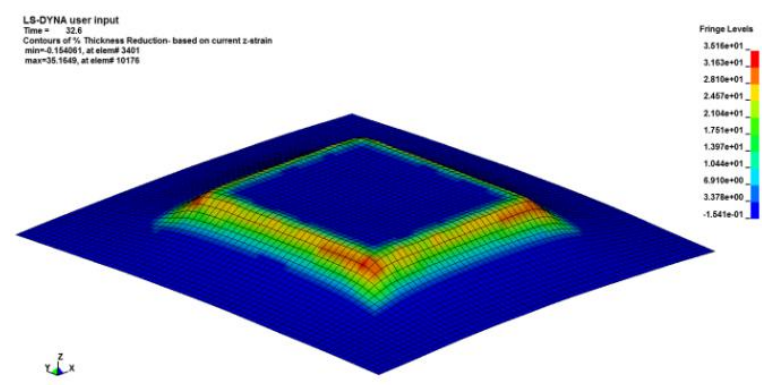

(b)

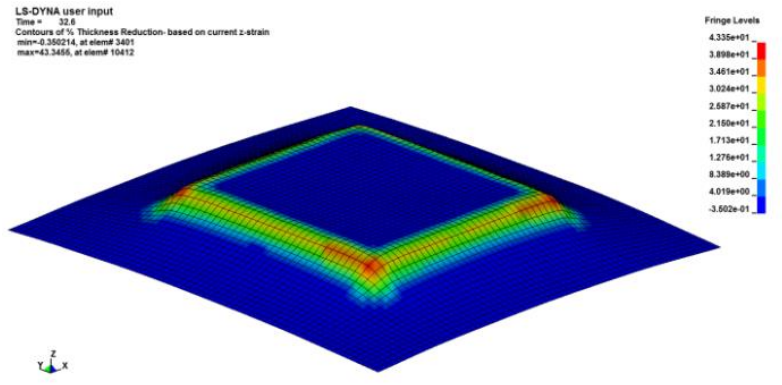


(c)

Figure 6: Thickness reduction variation for: the part with $45^{\circ}$ wall angle (a); the part with $55^{\circ}$ wall angle (b); the part with $65^{\circ}$ wall angle (c)

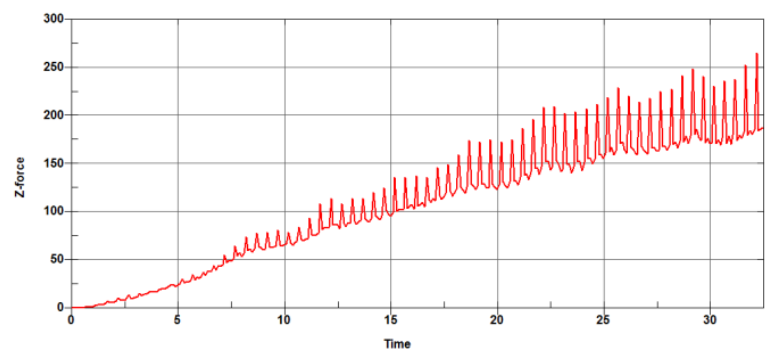

( a )

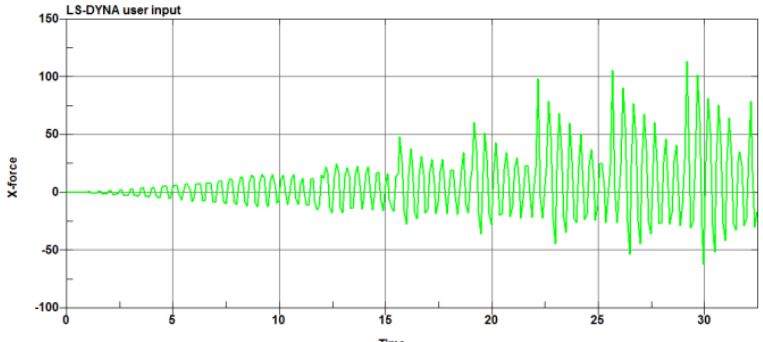

( b )

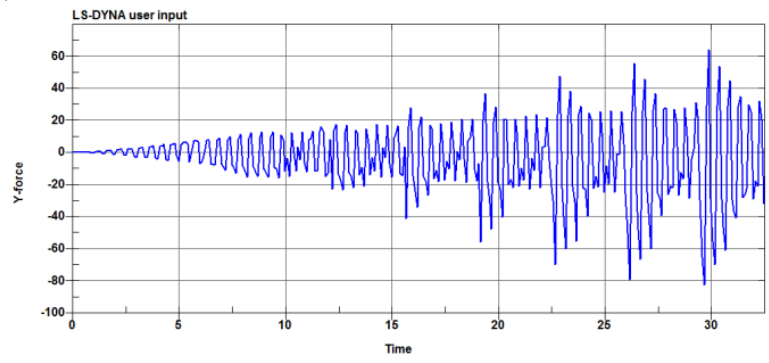

( c)

Figure 7: The forces variations on three different directions $(a)-F_{z},(b)-F_{x}$ and $(c)-F_{y}$ for the part with $45^{\circ}$ wall angle

Figure 6 presents the thickness reduction variations for the three different parts. It can be noticed that the thickness reduction variation is similar to the major strain variation. The maximum values obtained for the thickness reduction are: 25.63 [\%] - for the part with $45^{0}$ wall angle; 35.16 [\%] - for the part with $55^{\circ}$ wall angle and $43.35[\%]$ - for the part with $65^{\circ}$ wall angle.

Figure 7 presents the variation of forces on the three directions for the part with $45^{0}$ wall angle. It can be seen that, as expected, all three forces increase with the increase in the part height, there occurring local maxima at every vertical penetration of the punch (for the force $F_{z}$ ) and at each change of direction (for the forces $\mathrm{F}_{\mathrm{x}}$ and $\mathrm{F}_{\mathrm{y}}$ ), respectively. The maximum values obtained for the forces on $\mathrm{F}_{\mathrm{z}}$ are: 264.8 [N] - for the part with $45^{\circ}$ wall angle; $335.6[\mathrm{~N}]$ - for the part with $55^{\circ}$ wall angle and $342.41[\mathrm{~N}]-$ for the part with $65^{\circ}$ wall angle.

\section{Conclusions}

Following the analyses using the finite element method on the parts with different wall angles, following conclusions can be drawn:

- For the major strain and the thickness reduction there can be noticed an "inverse twist effect", an effect specific to incremental forming;

- The maximum values of major strain, minor strain and thickness reduction increase almost linearly with the increase of the wall wall angle;

- The maximum values of the forces also increase with the increase of the wall angle but the increase is slower at higher wall angle values (near the occurrence of necking). This is visible especially for the vertical force $\left(\mathrm{F}_{\mathrm{z}}\right)$, because for this force, as the wall angle increases, the pressure is done mostly on the $\mathrm{x}$ and $\mathrm{y}$ directions.

\section{References}

1. Alwood, J.M., Ustunomiya, H. A survey of flexible forming processes in Japan. International Journal of machine Tools \& Manufacture 46, pp. 1939-1960 (2006).

2. Ambrogio, G., Cozza, V., Filice, L., Micari, F. An analytical model for improving precision in single point incremental forming. Journal of Materials Processing Technology 191, 92-95 (2007).

3. Attanasio, A., Ceretti, E., Giardini, C., Mazzoni, L. Asymetric two points incremental forming: improving surface qualityand geometric accuracy by tool path optimization. Journal of Materials Processing Technology 197, pp. 59-67 (2008).

4. Bambach, M., Taleb Araghi, B., Hirt, G. Strategies to improve the geometric acuracy in asymetric single point incremental forming. Prod. Eng. Res. Devel. 3, pp. 145-156 (2009).

5. Behera, A. K., Verbert, J, Lauwers, B., Duflou, J.R. Tool path compensation strategies for single point incremental sheet forming using multivariate adaptive regression. Computer-Aided Design, 45, pp. 575-590 
(2013).

6. Capece Minutolo, F., Durante, M., Formisano, A., Langella, A., Evaluation of the maximum slope angle of simples geometries carried out by incremetnal forming process. Journal of Materials Processing Technology 194, pp. 145-150 (2007).

7. Duflou, J., Tunçkol, Y., Szekeres, A., Vanherck, P. Experimental study on force measurements for single point incremental forming. Journal of Materials Processing Technology 189, 65-72 (2007).

8. Filice, L., Ambrogio, G., Micari, F., On-Line Control of Single Point Incremental Forming Operations through Punch Force Monitoring. Annals of the CIRP 55 (1), pp. 245-248 (2006).

9. Fiorentino, A., Ceretti, E., Attanasio, A., Mazzoni, L., Giardini, C. Analysis of forces, accuracy and formability in positive die sheet incremental forming. Int J Mater Form, 2 (suppl.1), pp. 805-808, (2009).

10. Hussain, G., Dar, N.U., Gao, L., Chen, M.H., A comparative study on the forming limits of an aluminum sheetmetal in negative incremental forming. Journal of Materials Processing Technology 187-188, pp. 94-98 (2007).

11. Jackson, K.P., Allwood, J.M., Landert, M. Incremental forming of sandwich panels. Journal of Materials Processing Technology 204, pp. 290-303 (2008).

12. Martins, P.A.F., Kwiatkowski, L., Franzen, V., Tekkaya, A.E., Kleiner, M. Single point incremental forming of polymers. CIRP Annals - Manufacturing Technology 58, pp. 229-232 (2009).

13. Yamashita, M., Gotoh, M., Atsumi, S.-Y. Numerical simulation of incremental forming of sheet metal. Journal of Materials Processing Technology 199, 163-172 (2008). 